\title{
Titratable Pharmacological Regulation of CAR T Cells Using Zinc Finger-Based Transcription Factors
}

\author{
Bettina Kotter ${ }^{1}$, Fabian Engert ${ }^{1}$ (D), Winfried Krueger ${ }^{2}$, Andre Roy ${ }^{2}{ }^{(D}$, Wael Al Rawashdeh ${ }^{1}$, Nicole Cordes ${ }^{1}$, \\ Britta Drees ${ }^{1}$, Brian Webster ${ }^{1}$, Niels Werchau ${ }^{1}$, Dominik Lock ${ }^{1}$, Sandra Dapa ${ }^{1}$, Dina Schneider ${ }^{2}$, \\ Stephan Ludwig ${ }^{3}\left(\mathbb{D}\right.$, Claudia Rossig $^{4}$, Mario Assenmacher ${ }^{1}$, Joerg Mittelstaet ${ }^{1, *}$ and Andrew D. Kaiser ${ }^{1}$
}

1 Miltenyi Biotec B.V. \& Co. KG, Friedrich-Ebert-Straße 68, 51429 Bergisch Gladbach, Germany; bettinak@miltenyi.com (B.K.); fabiane@miltenyi.com (F.E.); waela@miltenyi.com (W.A.R.); nicolec@miltenyi.com (N.C.); brittad@miltenyi.com (B.D.); brianwe@miltenyi.com (B.W.); nielsw@miltenyi.com (N.W.); dominiklo@miltenyi.com (D.L.); sandrad@miltenyi.com (S.D.); mario@miltenyi.com (M.A.); andrewk@miltenyi.com (A.D.K.)

2 Lentigen Technology Inc., A Miltenyi Biotec Company, 910 Clopper Road, Suite 200 S, Gaithersburg, MD 20878, USA; Winfried.Krueger@miltenyi.com (W.K.); Andre.Roy@miltenyi.com (A.R.); Dina.Schneider@miltenyi.com (D.S.)

3 Interdisciplinary Center for Clinical Research (IZKF) and Institute of Virology (IVM), University Hospital Muenster, WWU, Von-Esmarch-Straße 56, 48149 Muenster, Germany; ludwigs@uni-muenster.de

4 Department of Pediatric Hematology and Oncology, University Children's Hospital Muenster, Albert-Schweitzer-Campus 1, 48149 Muenster, Germany; rossig@uni-muenster.de

* Correspondence: joergmi@miltenyi.com; Tel.: +49-2204-8306-2202

check for updates

Citation: Kotter, B.; Engert, F.; Krueger, W.; Roy, A.; Rawashdeh, W.A.; Cordes, N.; Drees, B.; Webster, B.; Werchau, N.; Lock, D.; et al. Titratable Pharmacological Regulation of CAR T Cells Using Zinc Finger-Based Transcription Factors. Cancers 2021, 13, 4741. https://doi.org/10.3390/ cancers13194741

Academic Editor: Alain P. Gobert

Received: 31 May 2021

Accepted: 17 September 2021

Published: 22 September 2021

Publisher's Note: MDPI stays neutral with regard to jurisdictional claims in published maps and institutional affiliations.

Copyright: (C) 2021 by the authors. Licensee MDPI, Basel, Switzerland. This article is an open access article distributed under the terms and conditions of the Creative Commons Attribution (CC BY) license (https:/ / creativecommons.org/licenses/by/ $4.0 /)$.
Simple Summary: Chimeric antigen receptor (CAR) T cell therapy can be associated with substantial side effects primarily due to intense immune activation following treatment, or target antigen recognition on off-tumor tissue. Consequently, temporal and tunable control of CAR T cell activity is of major importance for the clinical translation of innovative CAR designs. This work demonstrates the transcriptional regulation of an anti-CD20 CAR in primary $\mathrm{T}$ cells using a drug inducible zinc fingerbased transcription factor. The switch system enables titratable induction of CAR expression and CAR T cell effector function with the clinically relevant inducer drug tamoxifen and its metabolites both in vitro and in vivo, whereby CAR activity is strictly dependent on the presence of the inducer drug. The results obtained can readily be transferred to other CARs for which an improved control of expression is required.

Abstract: Chimeric antigen receptor (CAR) T cell therapy has emerged as an attractive strategy for cancer immunotherapy. Despite remarkable success for hematological malignancies, excessive activity and poor control of CAR T cells can result in severe adverse events requiring control strategies to improve safety. This work illustrates the feasibility of a zinc finger-based inducible switch system for transcriptional regulation of an anti-CD20 CAR in primary $\mathrm{T}$ cells providing small molecule-inducible control over therapeutic functions. We demonstrate time- and dose-dependent induction of anti-CD20 CAR expression and function with metabolites of the clinically-approved drug tamoxifen, and the absence of background CAR activity in the non-induced state. Inducible CAR T cells executed finetuned cytolytic activity against target cells both in vitro and in vivo, whereas CAR-related functions were lost upon drug discontinuation. This zinc finger-based transcriptional control system can be extended to other therapeutically important CARs, thus paving the way for safer cellular therapies.

Keywords: cellular immunotherapy; chimeric antigen receptor T cells (CAR T cells); transcriptional control

\section{Introduction}

Adoptive transfer of CAR-modified T cells is emerging as a promising treatment modality for a broad range of cancers. Most advanced in current clinical development 
is the treatment of B cell malignancies including acute and chronic B cell leukemia as well as B cell non-Hodgkin lymphoma with anti-CD19 CAR T cells that have recently been approved by the FDA [1-3]. Despite a pooled overall response rate of $71 \%$ across patients with B cell malignancies refractory to standard therapies [4], CAR T cell therapy is associated with unique acute and chronic side effects [5]. Cytokine release syndrome and neurotoxicity, the most commonly observed immediate adverse events, result from the excessive activity of CAR T cells upon antigen stimulation [6,7]. In addition, even low expression of the target antigen on normal tissue can result in on-target/off-tumor toxicities. In patients with B cell malignancies, on-target depletion of normal B cells causes B cell aplasia and resultant hypogammaglobulinemia [8,9]. Long-term follow-up studies have reported low remaining IgG levels for up to 4 years correlating with the persistence of the anti-CD19 CAR $\mathrm{T}$ cells resulting in a need for immunoglobulin replacement to reduce the susceptibility to infection in many patients [10-12]. On-target/off-tumor toxicities of CARs targeting alternative, non-B cell antigens may cause life-threatening toxicities if tissues of vital organs are damaged [13,14].

Different strategies have been developed to improve the safety of CAR T cell therapy [5]. Drug-based suicide switches as well as antibody-mediated depletion mechanisms are under clinical investigation for the elimination of adoptively transferred T cells [15-19]. Furthermore, several molecular approaches to control CAR T cells in a non-apoptotic manner have been evaluated to date [20-23]. Control of CAR-mediated function at the protein level has been achieved with anti-tag CAR technologies [21,22,24], reversible pharmacological on and off switches interfering with CAR signaling [23], or small molecule gated CARs where CAR function depends on the presence of a small molecule dimerizing the co-stimulatory domain and the CD3 $\zeta$ chain [20]. Targeting CAR expression rather than CAR signaling, a Tet-on-based transcription regulating circuitry represents a versatile tool for gene specific regulation [25]. However, high background expression in the non-induced state prevents the tight control of transgene expression in primary $\mathrm{T}$ cells limiting clinical application of the Tet-on system [26,27].

Alternatively, polydactyl zinc finger proteins assembled of modular zinc finger domains that recognize three contiguous base pairs of the DNA sequence each, can be designed to recognize DNA segments of specific length and sequence [28-31]. The attachment of an effector domain provides artificial transcription factors that efficiently activate, suppress, or create defined changes to the targeted promoters of both transgenes and endogenous genes [32-34]. Control of the transcription factor activity was achieved by fusing zinc finger domains to modified ligand-binding domains of steroid hormone receptors including the estrogen and progesterone receptor [35]. Key for achieving drug-targetable regulation is the unresponsiveness of the ligand-binding domains to the natural steroid ligands. By using a point-mutated, ligand-binding domain of the estrogen receptor in combination with the three finger zinc finger protein N1, Beerli and colleagues reported the efficient induction of reporter constructs with the inducer drug 4-hydroxytamoxifen (4-OHT), a hydroxylated metabolite of the FDA-approved drug tamoxifen, with no response to estrogen [35]. However, to our knowledge, synthetic zinc finger-based systems have not been used in primary $\mathrm{T}$ cells to control therapeutically relevant CARs.

Facing the hazardous side effects of CAR T cell therapy there is a high demand for the controlled regulation of transgene expression in adoptively transferred $\mathrm{T}$ cells. We employed a zinc finger-based 4-OHT inducible system to fine-tune CAR expression and, thereby, tightly control the cytolytic activity of CAR T cells in vitro and in vivo in a reversible manner. In the present study, we used the anti-CD20 CAR (scFv clone: Leu-16) as a model due to its well-established and published efficacy in tumor eradication [36]. In contrast to existing control strategies, the switch is not integrated into the CAR design and, thus, the functionally validated CAR structure is not disturbed. Using the investigated zinc finger-based system, virtually any CAR under clinical development could be controlled in an on/off switch manner characterized by high flexibility, selectivity, and tight controllability. 


\section{Results}

\subsection{Design of the Inducible Anti-CD20 CAR Construct}

For drug controlled transcription of the anti-CD20 CAR, a synthetic transcription factor composed of the $\mathrm{N} 1$ zinc finger protein, a modified ligand-binding domain of the estrogen receptor (G525R), and the transcriptional activation domain VP64 was constructed based on sequences reported by Beerli et al. [35] (Figure 1a). The synthetic transcription factor is constitutively expressed under the control of the human PGK promoter and linked via a P2A ribosome skip site to a truncated version of the low-affinity nerve growth factor receptor $(\triangle \mathrm{LNGFR})$, which serves as a transduction marker. In the presence of 4-OHT, the synthetic transcription factor binds to its respective binding sites and drives the transcription of the anti-CD20 CAR (Figure 1b). The second-generation anti-CD20 CAR is composed of the leader sequence from human granulocyte-macrophage colony-stimulating factor receptor alpha subunit (huGM-CSFR), a single-chain variable fragment targeting CD20, fused to the hinge and transmembrane domain of T cell surface glycoprotein CD8 alpha chain, and the intracellular signaling domains of the co-stimulatory receptor 4-1BB (CD137) followed by the intracytoplasmic region of CD3 [36,37]. The inducible element (binding sites-E1bmin-anti-CD20 CAR) was inserted into the vector in $3^{\prime}$ to $5^{\prime}$ direction to avoid read through and background transcription in the absence of the inducer drug. As a positive control, a constitutively expressed anti-CD20 CAR, referred to as direct CAR, was placed under the PGK promoter and linked to $\triangle \mathrm{LNGFR}$ via the P2A sequence.

\subsection{Drug Dependent Induction of Anti-CD20 CAR Expression and Induction Dynamics}

To study the induction capacity of this system, we transduced isolated primary human $\mathrm{T}$ cells with the drug-inducible lentiviral vector and induced the expression of the antiCD20 CAR by the addition of $100 \mathrm{nM} 4-\mathrm{OHT}$ to the cell culture medium. Anti-CD20 CAR expression on the surface of transduced $\left(\triangle \mathrm{LNGFR}^{+}\right) \mathrm{T}$ cells was measured by flow cytometry and revealed the selective induction of anti-CD20 CAR expression within $40 \mathrm{~h}$ of exposure to $100 \mathrm{nM} 4-\mathrm{OHT}$. No background expression was detectable in the non-induced state (Figures 1c and S1a,b, Table S1). Upon induction, inducible CAR T cells expressed significantly higher levels of anti-CD20 CAR, as measured by mean fluorescence intensity (MFI), compared to the conventional constitutively expressed CAR under the control of the PGK promoter (Figure 1d). Anti-CD20 CAR positive T cells could be detected as early as $4 \mathrm{~h}$ post-induction (Figure 1e). The frequency of anti-CD20 CAR expressing $\mathrm{T}$ cells as well as the CAR surface density (represented as MFI) increased over time and plateaued $8 \mathrm{~h}$ after the addition of $100 \mathrm{nM} 4-\mathrm{OHT}$ to the culture. Background levels of transgene expression were detected 10 days after discontinuation of $4 \mathrm{OHT}$ treatment for inducible anti-CD20 CAR constructs (Figures $1 \mathrm{f}$ and S1c,d). The persistence of the anti-CD20 CAR is likely due to surface stability of the protein. Therefore, destabilized GFP was used as a transgene to further characterize the system. Fast on and off switching by the zinc finger-based transcription factor was shown for destabilized GFP (Figure 1g,h). While expression rates were comparable (Figure 1g), decay rates were significantly faster for $\mathrm{T}$ cells induced to express a destabilized GFP reaching background expression levels $9 \mathrm{~h}$ after 4-OHT removal (Figures $1 \mathrm{~h}$ and S1c-e). These data point to tight transcriptional regulation with fast off-rates, and the absence of (neo-)transcription after inducer drug removal with transgene persistence depending mainly on the stability and half-life of the protein product. 
a

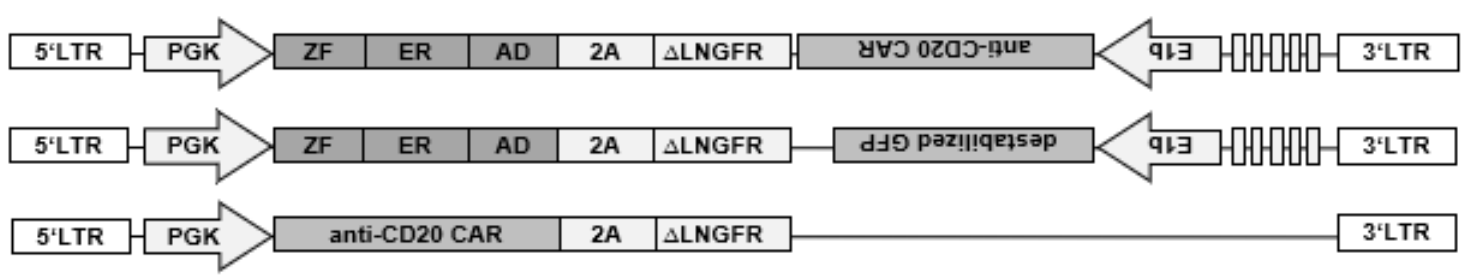

b

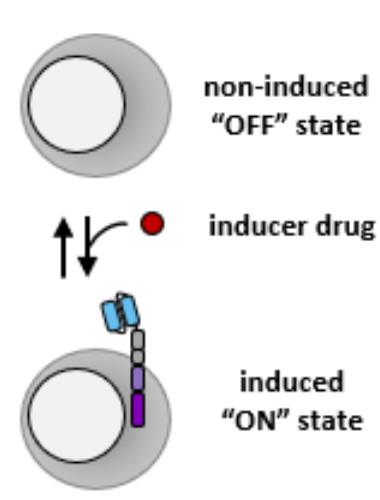

e

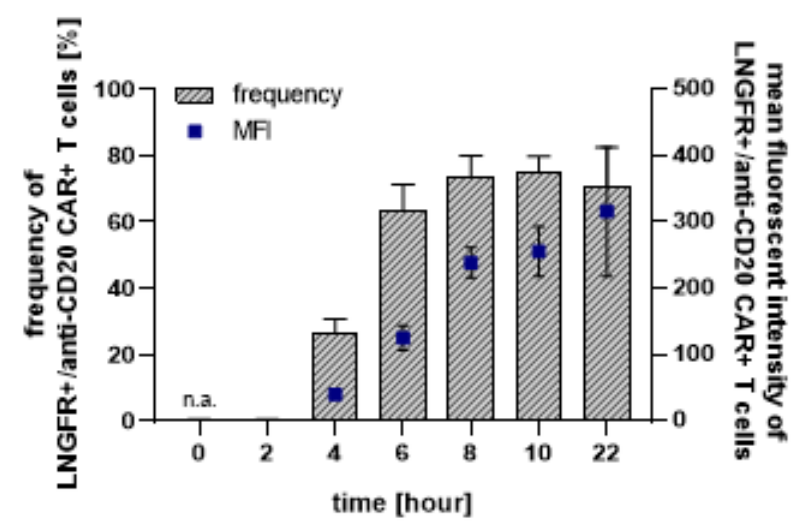

g

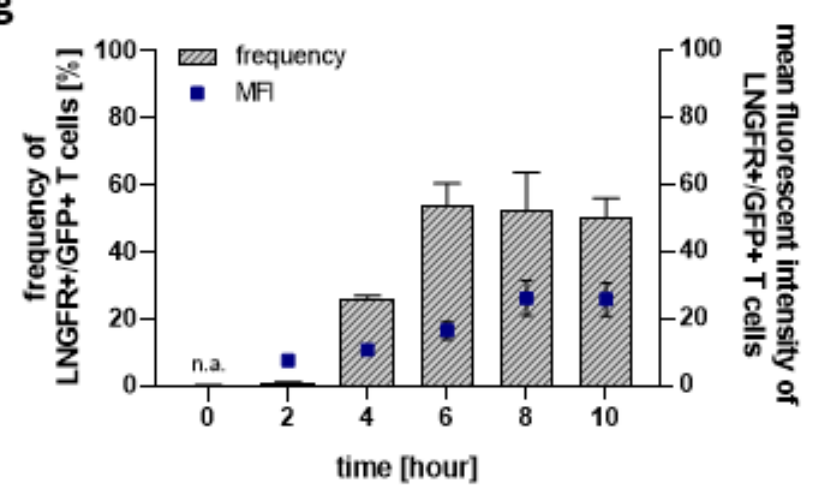

C

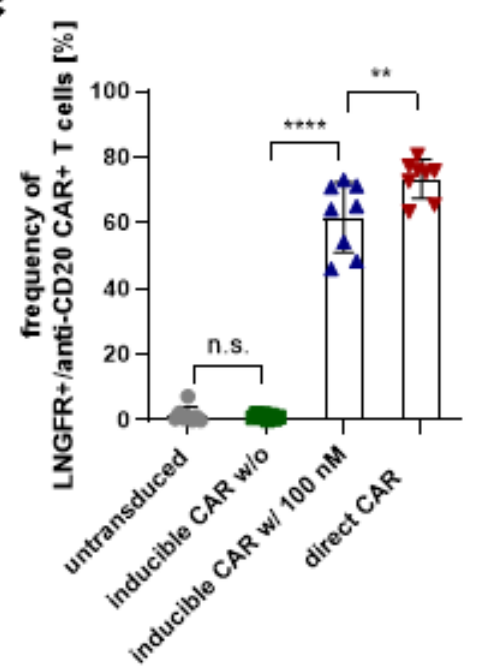

d

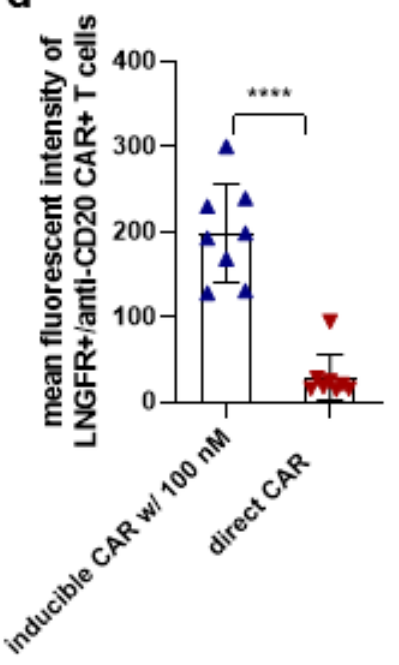

f

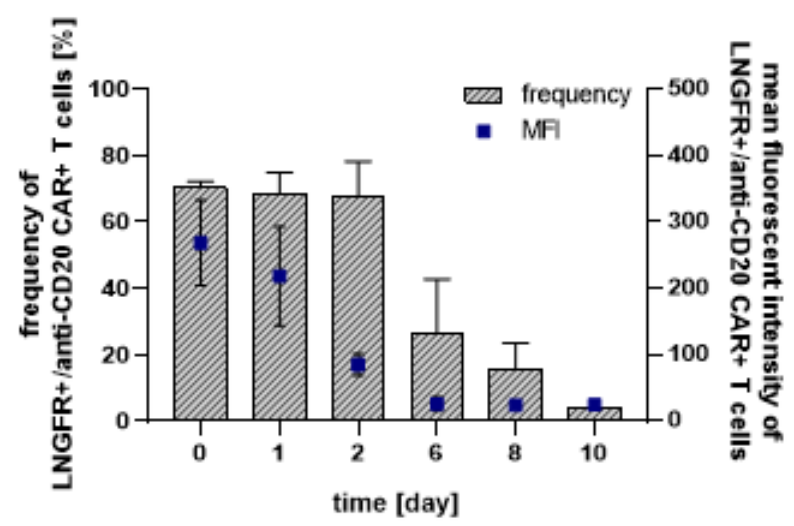

h

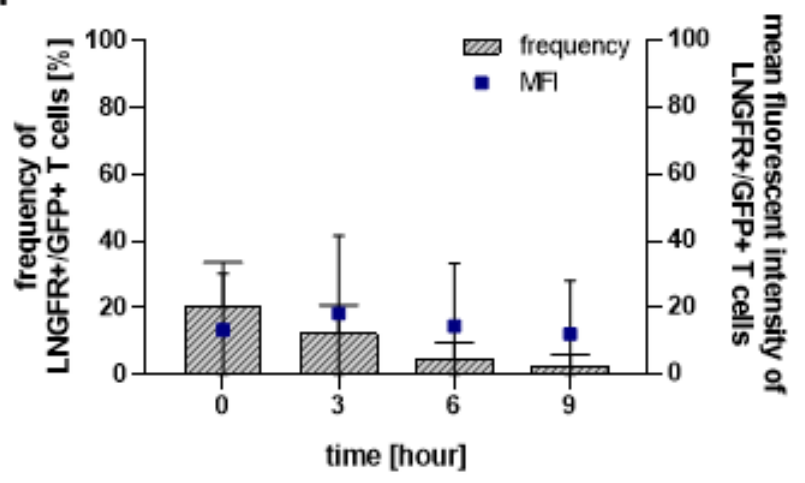

Figure 1. Drug dependent induction of anti-CD20 CAR expression and induction rates. (a) Schematic representation of the inducible anti-CD20 CAR, inducible destabilized GFP, and the conventional CAR construct. The constitutively expressed 
synthetic transcription factor is composed of the N1 zinc finger (ZF), an estrogen receptor (ER), and VP64 (AD). Transcription of the anti-CD20 CAR or destabilized GFP is initiated upon binding to its response elements upstream of the E1b minimal promoter. The conventional anti-CD20 CAR is constitutively expressed under the control of the PGK promoter and represents the positive control. $\triangle$ LNGFR is included in both constructs as a transduction marker. (b) Schematic illustration of the mode of action. In the presence of the inducer drug (4-OHT, endoxifen) transcription and, thus, the expression of the anti-CD20 CAR in primary T cells are triggered. In the absence of the inducer, $\mathrm{T}$ cells do not express the anti-CD20 CAR. $(\mathbf{c}, \mathbf{d})$ Cell surface expression of anti-CD20 CAR amongst $\triangle$ LNGFR expressing cells was determined $40 \mathrm{~h}$ after the induction with $100 \mathrm{nM} 4$-OHT by flow cytometry using anti-CD20 CAR detection reagent-PE. Data for frequency (c) and MFI (d) of anti-CD20 CAR T cells are normalized to the expression of the transduction marker $\triangle$ LNGFR. (e) Cell surface expression of anti-CD20 CAR was analyzed at indicated time points after the induction with $100 \mathrm{nM} 4-\mathrm{OHT}$ by flow cytometry and normalized to the expression of $\triangle$ LNGFR. (f) Inducible CAR T cells were induced with $100 \mathrm{nM}$ for $40 \mathrm{~h}$ and anti-CD20 CAR expression was determined for the indicated time points after 4-OHT discontinuation. (g) Expression of destabilized GFP was analyzed at indicated time points in primary T cells after the induction with $100 \mathrm{nM} 4-\mathrm{OHT}$ by flow cytometry and normalized to the expression of $\triangle$ LNGFR. (h) GFP expression in T cells was induced with $100 \mathrm{nM} 4-\mathrm{OHT}$ for $40 \mathrm{~h}$ and determined for the indicated time points after 4-OHT discontinuation. Graphs represent data from $n=8(\mathbf{c}, \mathbf{d}) ; n=3$ (e-h) different donors. Data shown are mean values \pm s.d. with ${ }^{* *} p<0.01,{ }^{* * * *} p<0.0001$ by one-way analysis of variance (ANOVA) (c), or by unpaired two-tailed t test (d). n.s.: not statistically significant.

\subsection{Inducible CAR T Cells Show Efficient Cytotoxic Activity in the Presence of 4-OHT, While CAR-Related Functions Are Lost after 4-OHT Discontinuation In Vitro}

To assess the cytolytic activity of inducible CAR T cells, we performed co-cultures with $\mathrm{CD}^{2} 0^{+}$target cells in the presence or absence of $100 \mathrm{nM} 4-\mathrm{OHT}$. GFP ${ }^{+}$526-Mel cells were genetically modified to express high levels of the CD20 target antigen (Figure S2a). Upon induction, inducible anti-CD20 CAR T cells efficiently eradicated GFP+ CD20+526-Mel and achieved the same level of specific lysis as constitutively expressed control CAR T cells, whereas we did not detect target cell lysis in parallel cultures without 4-OHT (Figure 2a). In addition, cytokine secretion by inducible CAR T cells upon antigen engagement was strictly dependent on the presence of 4-OHT with cytokine levels below background in the non-induced state. The induction of CAR T cells resulted in a 400-fold increase in IFN- $\gamma$ levels and a 70,000-fold increase in IL-2 levels, respectively. While IL-2 levels secreted by inducible CAR T cells in co-cultures with $\mathrm{GFP}^{+} \mathrm{CD} 20^{+}$526-Mel were significantly higher compared to the conventional constitutively expressed CAR, IFN- $\gamma$ levels were comparable (Figure 2b,c). Maximum specific lysis of $\mathrm{GFP}^{+} \mathrm{CD} 20^{+} 526-\mathrm{Mel}$ was obtained already at a concentration of $10 \mathrm{nM} 4-\mathrm{OHT}\left(\mathrm{EC}_{50}=3.6 \mathrm{nM}\right)$, thus matching the physiological concentration of 4-OHT detected in breast cancer patients treated with tamoxifen [38]. Endoxifen, a less potent but more prevalent metabolite of tamoxifen, induced cytolytic activity at a higher $\mathrm{EC}_{50}$ value of $=28.2 \mathrm{nM}$ (Figure $2 \mathrm{~d}$ ). In vitro, inducible CAR T cells eradicated $\mathrm{GFP}^{+} \mathrm{CD}_{20}{ }^{+}$526-Mel about as efficiently as conventional constitutively expressed CAR $\mathrm{T}$ cells even at low effector-to-target cell (E-T) ratios (Figure 2e) demonstrating serial killing capacity and induced killing even if 4-OHT was added at later time points to the co-culture (Figure 2f). Next, we investigated whether activated, inducible CAR T cells lose CAR-related functions after 4-OHT discontinuation. Following efficient lysis of CD20 tumor cells (round 1), T cells were washed and re-co-cultured with freshly plated tumor cells. Although 4-OHT was removed, inducible CAR T cells continued to eradicate $\mathrm{GFP}^{+}$ $\mathrm{CD}^{+} 0^{+}$526-Mel (Figures $2 \mathrm{~g}$ and S2b). We reasoned that tumor cell lysis was mediated by the remaining anti-CD20 CAR molecules rather than the synthesis of new proteins. Accordingly, we performed a sequential stimulation study. In the third serial co-culture, cytolytic activity was lost in the absence of 4-OHT. While the conventional constitutively expressed anti-CD20 CAR did not eradicate tumor cells in the third round, inducible CAR $\mathrm{T}$ cells controlled tumor outgrowth in the presence of 4-OHT (Figure 2g). 
a

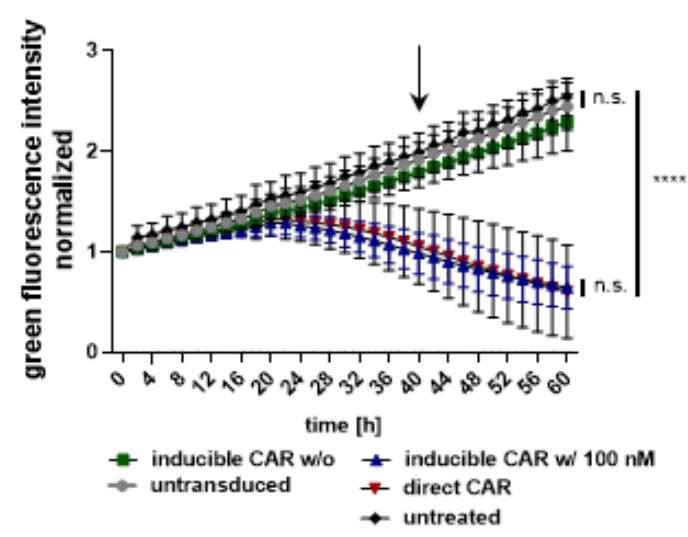

b

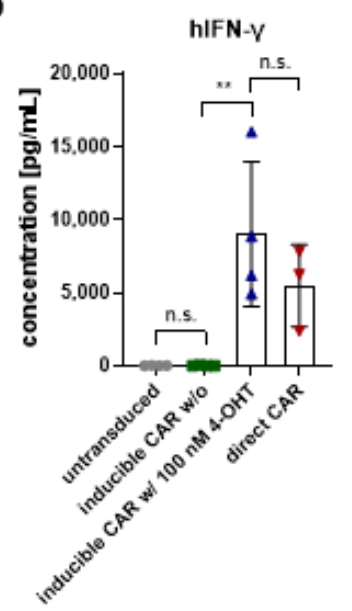

C

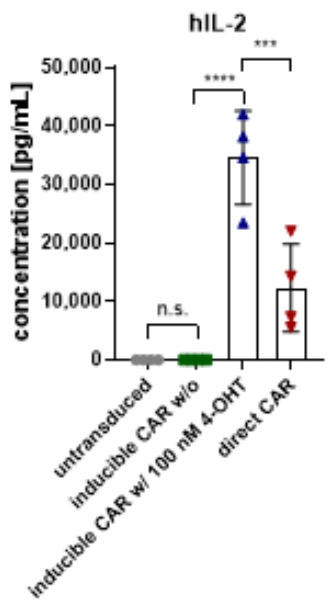

d
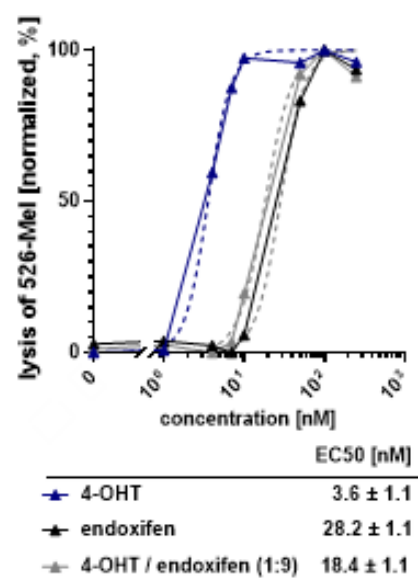

e

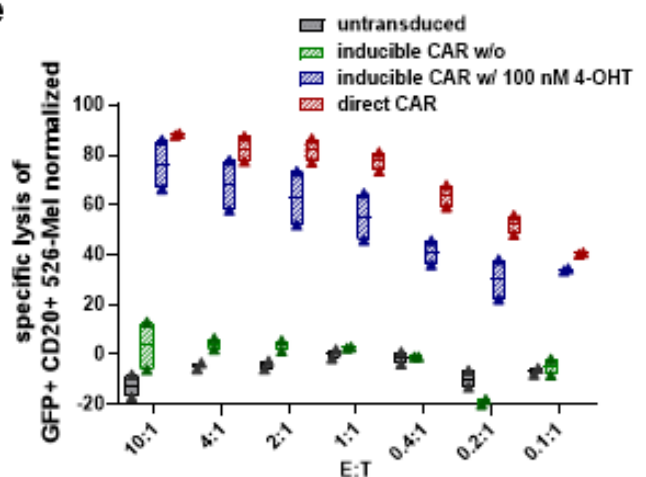

f

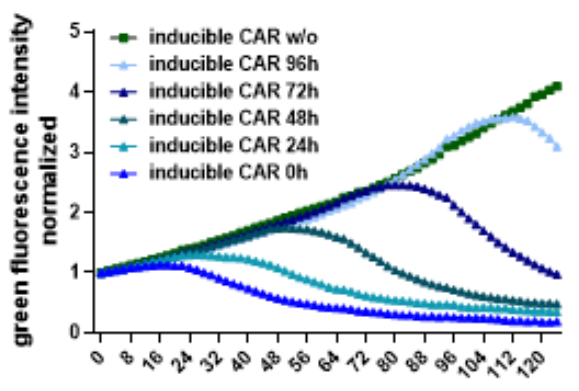

time [h] g

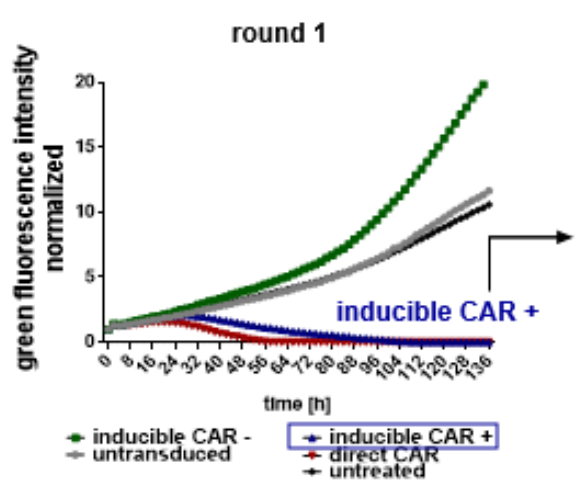

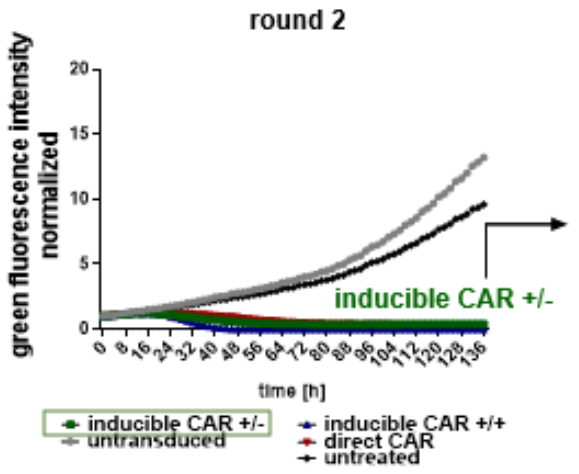

round 3

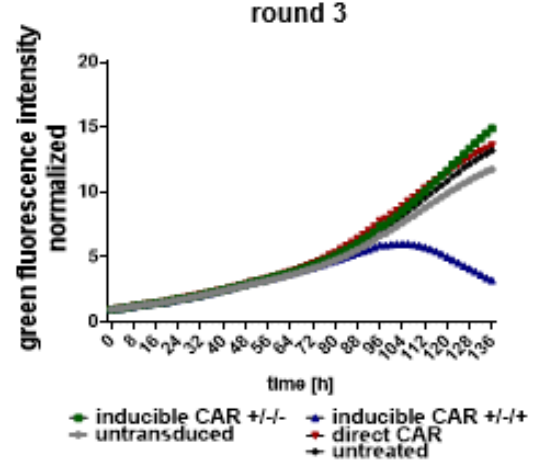

Figure 2. Inducible CAR T cells show efficient cytotoxic activity in the presence of 4-OHT, while CAR-related functions are lost after 4-OHT discontinuation in vitro. (a) $\mathrm{T}$ cells expressing $\triangle \mathrm{LNGFR}$ were co-cultured with $\mathrm{GFP}^{+} \mathrm{CD} 20+526-\mathrm{Mel}$ at an E-T ratio of 1:1 in the presence of $100 \mathrm{nM} 4-\mathrm{OHT}$ added at the start of the assay. T cell numbers were adjusted to LNGFR expression implicating equal transduced and total $\mathrm{T}$ cell numbers in each well. Growth of $\mathrm{GFP}^{+} \mathrm{CD} 20^{+} 526-\mathrm{Mel}$ was monitored in $2 \mathrm{~h}$ intervals over a period of $60 \mathrm{~h}$ using a live-cell imaging device (IncuCyte). The arrow indicates the time point of cytokine analysis. (b,c) The concentration of human IFN- $\gamma(\mathbf{b})$ and IL-2 (c) was analyzed in the supernatant $40 \mathrm{~h}$ after assay initiation by MACSPlex Cytokine $12 \mathrm{Kit}$. (d) Inducible CAR T cells were co-cultured with $\mathrm{GFP}^{+} \mathrm{CD}^{+} \mathrm{O}^{+}$ 526-Mel at an E-T ratio of 1:1 in the presence of varying concentrations of 4-OHT and/or endoxifen. Specific lysis of GFP ${ }^{+}$ $\mathrm{CD} 20^{+}$526-Mel was measured $40 \mathrm{~h}$ after co-culture setup, log transformed and normalized. Non-linear regression was performed to calculate $\mathrm{EC}_{50}$ values. (e) Cytolytic activity of $\mathrm{T}$ cells against $\mathrm{GFP}^{+} \mathrm{CD} 20^{+} 526-\mathrm{Mel}$ at varying $\mathrm{E}-\mathrm{T}$ ratios was assessed $40 \mathrm{~h}$ after co-culture set-up in the presence or absence of $100 \mathrm{nM}$ 4-OHT. (f) The inducer drug 4-OHT was added at 
different time points at a concentration of $100 \mathrm{nM}$ to the co-culture of inducible CAR T cells and GFP ${ }^{+}$CD20+ 526-Mel. (g) T cells were co-cultured with $\mathrm{GFP}^{+} \mathrm{CD}^{+} 0^{+}$526-Mel at an E-T ratio of 1:1 in the presence of $100 \mathrm{nM} 4-\mathrm{OHT}$ added at the start of the assay. After each co-culture, T cells were harvested and 4-OHT was removed. T cells were then transferred onto new tumor cells in the absence (-) or presence (+) of $100 \mathrm{nM} 4-\mathrm{OHT}$. Growth of GFP ${ }^{+}$CD20 $0^{+}$526-Mel was monitored in $2 \mathrm{~h}$ intervals and expressed as normalized green fluorescence intensity. In $(\mathbf{f}, \mathbf{g})$ graphs represent pooled results of different donors generated within one experiment. Graphs show data from $n=5(\mathbf{a}) ; n=4(\mathbf{b}, \mathbf{c}) ; n=3(\mathbf{d}) ; n=2$ (e-g) different donors. Data shown are mean values \pm s.d. with ${ }^{* *} p<0.01,{ }^{* * *} p<0.001,{ }^{* * * *} p<0.0001$ by two-way analysis of variance (ANOVA) (a), or by one-way ANOVA (b,c). n.s.: not statistically significant.

\subsection{Titration of Inducer Dose and Reduction of Response Elements Enables Fine-Tuning of Inducible Anti-CD20 CAR Activity}

We titrated the 4-OHT concentration and reduced the number of response elements for the synthetic transcription factor to investigate whether we can fine-tune anti-CD20 CAR expression and, thus, precisely control the cytolytic activity of inducible CAR T cells. Titration experiments revealed that with an increasing drug dose and an increasing number of binding sites per construct, the frequency of T cells expressing the anti-CD20 CAR over detection limit can be maximized (Figure 3a). However, surface expression (represented as MFI) did not reach saturation within the titrated range (Figure 3b). Importantly, for all constructs, CAR expression in T cells was absolutely dependent on the presence of the inducer drug, and strict transcriptional control was maintained after polyclonal activation (Figure S1f,g). CAR-mediated activity was efficiently triggered in T cells incorporating constructs with two or more binding sites and was promoted with increasing concentrations of 4-OHT. Different combinations of the two modulatory entities (supplementation of 4-OHT and number of binding sites) resulted in distinct levels of IFN- $\gamma$ and IL-2 as well as killing potential in co-culture with $\mathrm{GFP}^{+} \mathrm{CD}^{2} 0^{+}$526-Mel cells and allowed for a controlled, fine-tuned on switch (Figure 3c-e). Similar results were obtained for co-cultures with the Burkitt lymphoma cell line Raji (Figure 3f-h). Inducible anti-CD20 CAR T cells efficiently eradicated $\mathrm{GFP}^{+}$Raji cells in a dose-dependent manner and achieved the same level of specific lysis as conventional constitutively expressed CAR T cells, whereas we did not detect target cell lysis in parallel cultures without 4-OHT (Figures 3h and S2c). IFN- $\gamma$ and IL-2 secretion were strictly dependent on the presence of the inducer drug (in this case 4-OHT) and cytokine levels could be modulated by the concentration of 4-OHT as well as by the number of binding sites (Figures $3 f, g$ and S2d,e).

\subsection{Inducible CAR T Cells Efficiently Eradicate Disseminated Lymphoma In Vivo}

As tight expression control is a key feature of drug-inducible CAR T cells, an in vivo study was designed to detect any potential residual CAR activity in the absence of the inducer drug, as well as to analyze therapeutic activity of the CD20 CAR T cells in its presence. Therefore, we applied a progressive model of Burkitt lymphoma (RajiffLuc cells) in immunodeficient NOD.Cg-Prkdc scid $I L-2 r g^{t m 1 W j l} / \mathrm{SzJ}$ (NSG) mice. Mice received $3 \times 10^{6}$ transduced $\left(\triangle \mathrm{LNGFR}^{+}\right) \mathrm{T}$ cells in a total of $1.1 \times 10^{7} \mathrm{~T}$ cells, or $1.1 \times 10^{7}$ control $\mathrm{T}$ cells intravenously (i.v.) on day 0 . Tamoxifen was administered by intraperitoneal (i.p.) injections to the indicated groups starting on day 1. Tumor burden was assessed by bioluminescent imaging (BLI, Figure 4a). Inducible CAR T cells in combination with tamoxifen treatment completely eradicated disseminated lymphoma within 19 days of the $\mathrm{T}$ cell injection. Killing kinetics were slightly delayed compared to the conventional constitutively expressed anti-CD20 CAR. In contrast, tumor burden (seen in photon flux in Figure 4c) in the inducible CAR group not receiving tamoxifen progressed similarly to the control groups (untransduced T cells, untreated), demonstrating strict transcriptional control of the inducible CAR cassette. Importantly, tamoxifen-treated mice in the inducible CAR group remained in complete remission throughout the study course of 35 days (Figure $4 b, c)$. Dosing experiments demonstrated that the cytolytic activity of inducible CAR T cells can be controlled in vivo by the tamoxifen dose and the injection frequency (Figure S3a,b). The highest anti-CD20 CAR expression on $\mathrm{T}$ cells in the bone marrow 
was detected in the groups treated with daily injections of $1 \mathrm{mg}$ tamoxifen, while less tamoxifen or an increased administration interval resulted in less effective induction and, thus, reduced tumor control (Figure S3c). Active metabolites of tamoxifen reached plasma levels, which could effectively induce ex vivo killing of tumor cells (Figure S3d). Plasma cytokine analysis demonstrated a specific tamoxifen-dependent activation of inducible CAR T cells in vivo. Significant levels of IFN- $\gamma$ and IL-2 were detected in the plasma on day 2 of mice receiving inducible CAR T cells in combination with daily tamoxifen injections compared to control groups, while only background secretion was detected in the non-induced state (Figure 4d,e). Inducible T cells, isolated from the spleen on day 35 after the $\mathrm{T}$ cell injection, could be re-induced ex vivo to efficiently express the anti-CD20 CAR by the administration of $100 \mathrm{nM} 4-\mathrm{OHT}$, demonstrating the possibility to control therapy by on and off switching (Figures $4 \mathrm{f}$ and $\mathrm{S} 4$ ).

a

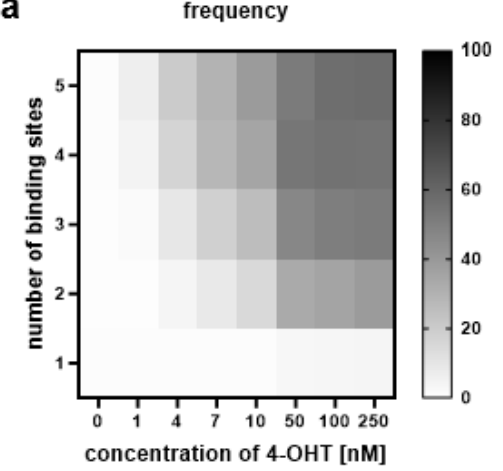

C

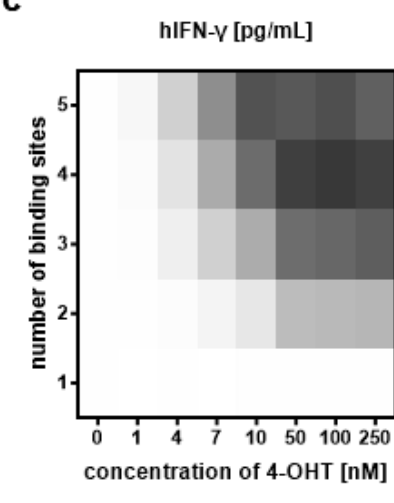

f

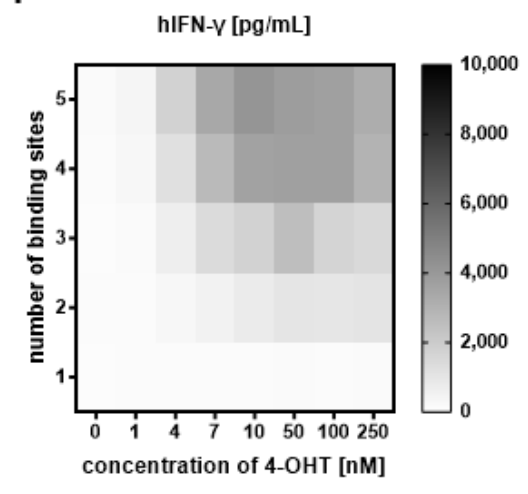

b

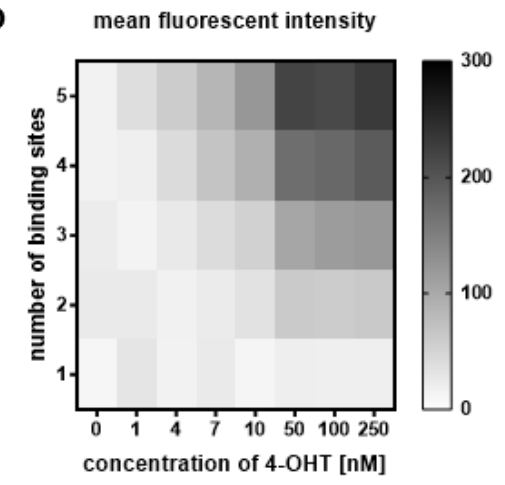

d

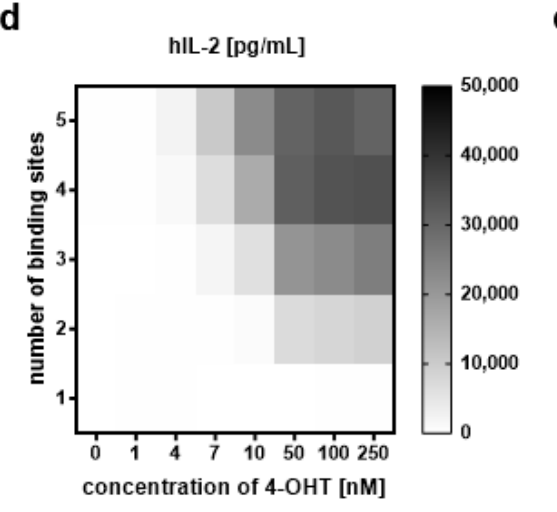

g

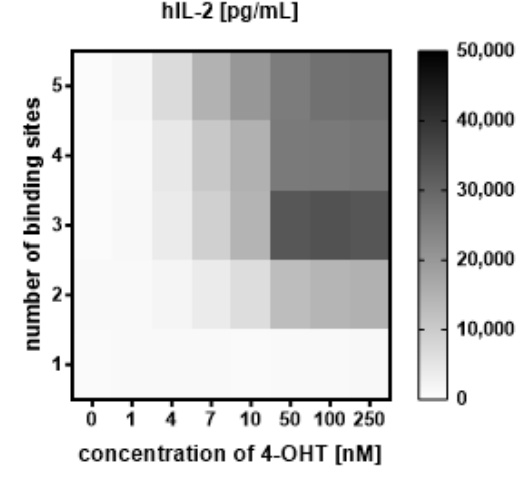

e

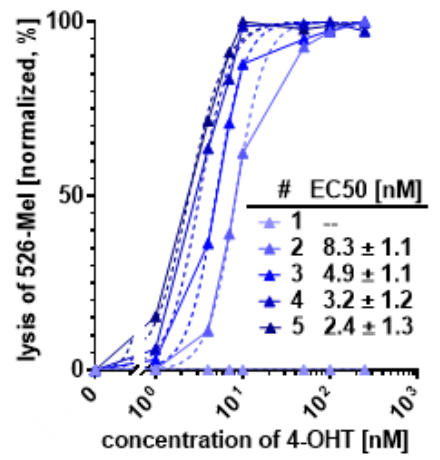

h

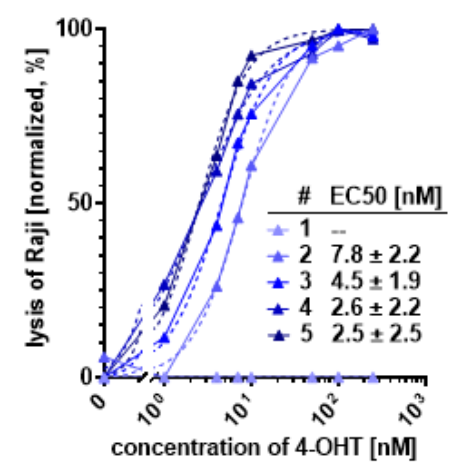

Figure 3. Modulation of anti-CD20 CAR induction by the inducer dose and the number of response elements. (a,b) Inducible CAR T cells bearing one to five binding sites for the synthetic transcription factor were induced with varying concentrations of 4-OHT. Cell surface expression of anti-CD20 CAR was determined after $40 \mathrm{~h}$ by flow cytometry using anti-CD20 CAR detection reagent-PE. Data for frequency (a) and MFI (b) of anti-CD20 CAR T cells are normalized to the expression of the transduction marker $\triangle$ LNGFR. (c-h) Inducible CAR T cells bearing one to five binding sites for the synthetic transcription 
factor were co-cultured with GFP ${ }^{+} \mathrm{CD}^{+} 0^{+}$526-Mel (upper panel) or GFP ${ }^{+}$Raji (lower panel) for $40 \mathrm{~h}$ at an E-T ratio of 1:1 in the presence of varying concentrations of 4-OHT. (c,d,f,g) Human IFN- $\gamma$ and IL-2 levels were detected in the culture supernatant by MACSPlex Cytokine $12 \mathrm{Kit}$. (e,h) Titration curves were determined for the lysis of GFP ${ }^{+} \mathrm{CD}^{+} 0^{+}$526-Mel and $\mathrm{GFP}^{+}$Raji. Non-linear regression was performed to calculate $\mathrm{EC}_{50}$ values following log transformation and normalization of data. Graphs show data from $n=5(\mathbf{a}, \mathbf{b}, \mathbf{e}, \mathbf{h}) ; n=2(\mathbf{c}, \mathbf{d}, \mathbf{f}, \mathbf{g})$ different donors.

a

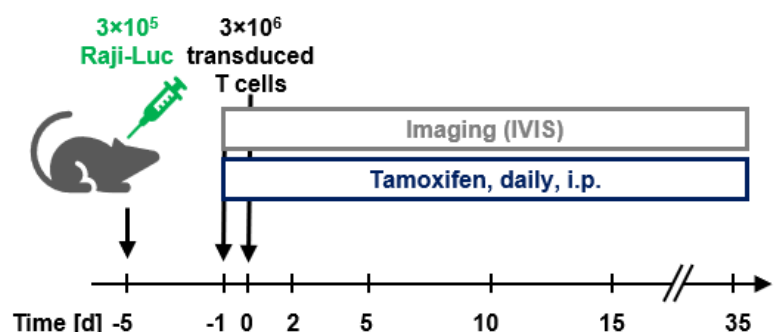

C

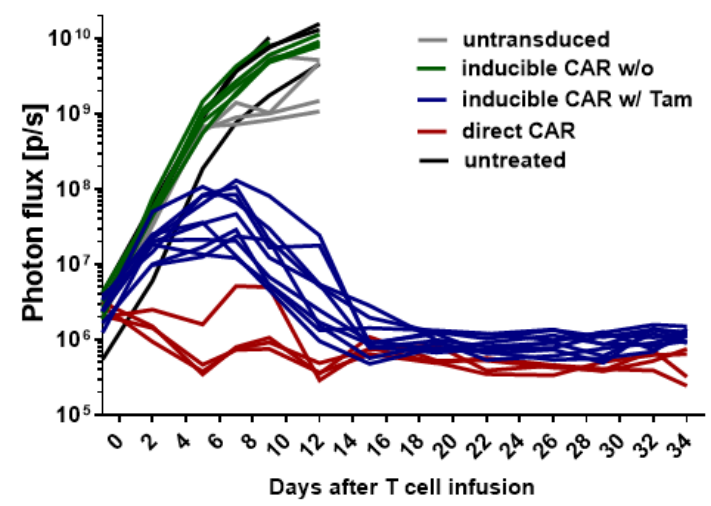

b

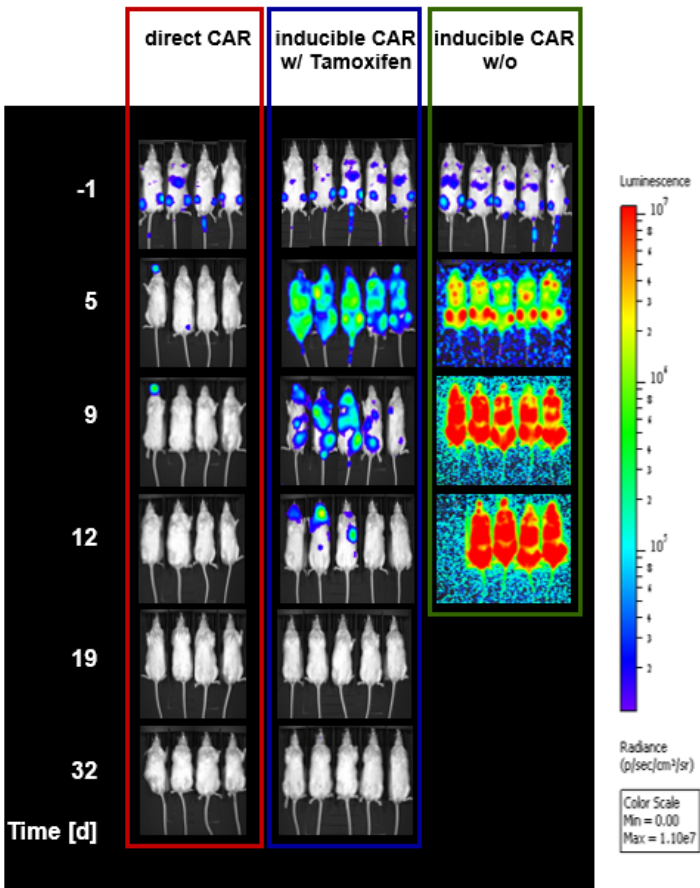

f

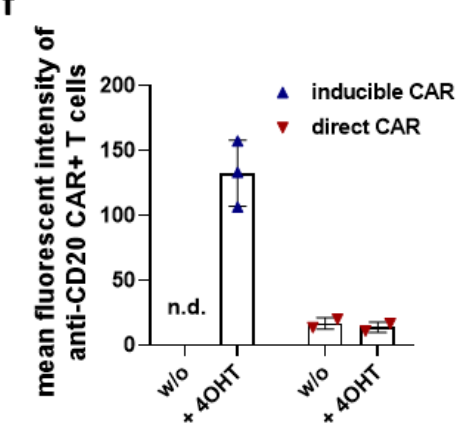

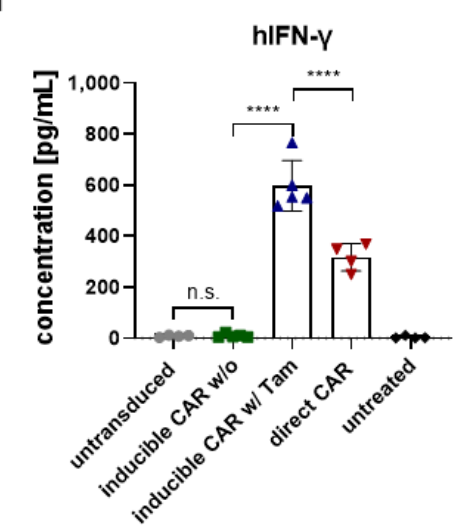

e

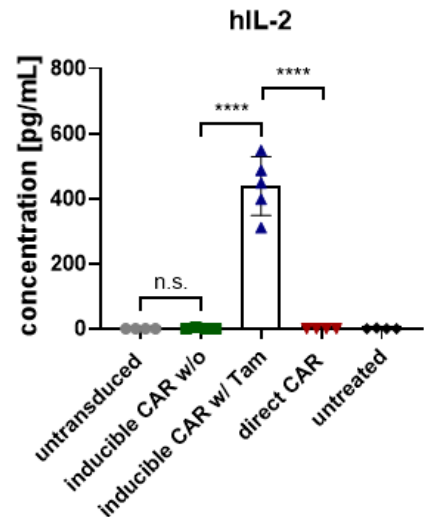

Figure 4. Cytotoxic activity of inducible anti-CD20 CAR T cells in vivo. (a) Schematic representation of the in vivo treatment schedule. NSG mice were inoculated with $3 \times 10^{5}$ Rajiffuc cells via tail vein injection on day 5 . On day 0 , following randomization, mice were treated with untransduced, inducible, or conventional constitutively expressed anti-CD20 CAR T cells. Starting from day -1 tamoxifen was administered daily by i.p. injections to the untreated (= tumor only), untransduced, and inducible CAR w/ Tam groups, while the constitutively expressed direct CAR and the inducible CAR w/o groups received vehicle injections only. The tumor burden was regularly determined by in vivo BLI. (b) BLI images represent tumor progression in selected study groups. (c) Tumor burden expressed in photon flux (photons/sec) was determined and plotted over time for individual mice. $(\mathbf{d}, \mathbf{e})$ Human cytokines were measured in the plasma of individual mice 2 days after T cell infusion. Data represent means from $n=5$ (inducible CAR \pm Tam) and $n=4$ (control groups). Data shown are mean values \pm s.d. with ${ }^{* * * *} p<0.0001$ by one-way analysis of variance (ANOVA). (f) Ex vivo cultivated T cells isolated via $\mathrm{CD}^{+} / \mathrm{CD}^{+}$enrichment from the spleen of individual mice were induced with $100 \mathrm{nM} 4-\mathrm{OHT}$ for $46 \mathrm{~h}$ and analyzed for anti-CD20 CAR expression via flow cytometry. Data represent the MFI of anti-CD20 CAR. The frequency of anti-CD20 CAR expressing cells is shown in Figure S4. 


\section{Discussion}

CAR T cell therapy targeting the CD19 antigen has demonstrated significant clinical benefit in hematological malignancies [1-3]. However, along with therapy, unwanted side effects have been reported including late effects that can persist throughout the life span of the transferred T cells [5]. Effective toxicity management and prevention requires control over CAR T cell functions after administration into patients, raising the need for a reversible remote control acting in an on/off manner.

In the present study, we demonstrated the use of a tamoxifen-dependent inducible control system based on a previously described transcription factor [35] for the tight control of anti-CD20 CAR expression in primary T cells. Our data illustrate specific induction of anti-CD20 CAR expression in the presence of the inducer drug with no background expression in the non-induced state, differentiating this system from other transcriptional control systems, in particular the Tet-on system for CAR regulation [26,39]. Maximum expression levels for the inducible CAR were up to 7-fold higher compared to the conventional constitutively expressed anti-CD20 CAR (Figure 1d), presumably due to the distinct promoter composition in conjunction with the recruited transcription factors [40]. Despite differences in CAR expression levels between the inducible CAR and the conventional constitutively expressed CAR, tumor cell lysis and IFN- $\gamma$ secretion in vitro was equally efficient (Figures 2a,b and S2c,d). Previous studies reported an impaired antitumor effect of $\mathrm{T}$ cells with low CAR expression compared to high CAR levels, especially at low antigen densities [41-43]. On the other hand, CAR expression beyond the threshold for effective $\mathrm{T}$ cell activation was reported to contribute to a tonic signaling signature and $\mathrm{T}$ cell differentiation impairing the in vivo anti-tumor activity [44]. The possible implications of inducible CAR T cells enabling the precise regulation of receptor densities on the T cell surface beyond baseline transcriptional control need to be further evaluated in settings where the target antigen is expressed at lower and/or heterogeneous densities on tumor cells. In particular, with regard to reported differences between in vitro and in vivo studies in terms of optimal CAR expression levels, precise tuning of CAR densities and their adjustment to the patient's conditions might allow CAR T cells to discriminate between different biological contexts and, thereby, become safe and also effective against tumor cells that share target antigens with normal tissues.

$\mathrm{EC}_{50}$ concentrations of 4-OHT and endoxifen required for the specific lysis of tumor cells in vitro are below the physiological concentration of the hydroxylated tamoxifen metabolites that can readily be found in breast cancer patients treated with a daily oral dose of $20 \mathrm{mg}$ tamoxifen [38] (Figure 2d). Endoxifen is present in the blood at higher concentrations than 4-OHT, while 4-OHT displays a higher affinity for the estrogen receptor $[38,45]$. Side effects of tamoxifen are mainly associated with its demethylated metabolites and related to its hormonal mode of action. These include, among others, hot flushes, fatigue, vaginal dryness, sleep problems, weight gain, mood swings, and depression [46]. Patients treated with tamoxifen over a period of 5 years have been reported to be at higher risk for thromboembolic events and the development of endometrial cancer during the active treatment period [47]. Overall, tamoxifen-related side effects have been well described, are clinically manageable, and might be acceptable in the context of controlling CAR T cell activity, especially if subtherapeutic doses can be used. Furthermore, the direct application of active metabolites requires even lower doses for effective induction [48] and, thereby, could further minimize the risk of associated side effects.

Conventional kill switches are off switches resulting in an irreversible termination of CAR T cell activity. The activation of drug-based suicide switches, including herpes simplex virus thymidine kinase and dimerizing death molecules (Fas, iCas9), results in cell death within 30 min of administration [15-17]. For selective antibody-mediated depletion, cells are engineered to express a targetable moiety such as CD20, tEGFR, or CD34 with subsequent apoptosis triggered by the administration of the cognate antibody $[18,19]$. Besides suboptimal expression levels and the resistance of cells to kill switches limiting 
the efficacy, the irreversible termination of the CAR-mediated anti-tumor effect might be problematic if the patient requires reactivation [15-17].

In contrast, our system allows the management of toxicity by terminating tamoxifen administration, resulting in pausing of the CAR $\mathrm{T}$ cell-mediated effects with the possibility of re-inducing CAR expression at later time points. Our study revealed that the re-induction of CAR expression after an on/off phase is feasible, demonstrating complete reversibility of CAR activity (Figures $4 \mathrm{f}$ and S4). Thereby, reinfusion of the CAR T cells in case of relapse can be avoided, minimizing patient stress and lowering financial burden. A potential limitation of the tamoxifen-inducible system for the control of anti-CD20 CARs is the slow transition to the off state seen in vitro, as well as the half-life of tamoxifen in vivo. Based on the decay rate determined for destabilized GFP, we hypothesize that the system itself has fast switching kinetics, but it is limited by the stability of the anti-CD20 CAR on the T cell surface (Figures 1e-h and S1c-e).

The relatively long half-life of tamoxifen [49] as well as the lag period until CAR densities reach below the critical threshold required for effector function (Figure 2g), will limit rapid intervention, e.g., for the treatment of life-threatening cytokine release syndrome. However, through combination therapy, e.g., with tocilizumab [50] providing IL-6 receptor blockade, acute adverse events can be controlled temporarily. During this time window, downregulation of CAR expression and associated activities could be realized, enabling the reversible suspension of the therapy. In clinical situations where very rapid intervention is not required, the tamoxifen-regulated system could significantly contribute to the quality of life for patients. The suspension of anti-CD20 CAR T cell function may, for instance, allow the reversal of long-term B cell aplasia and, thus, replace the need for extended, possibly lifelong immunoglobulin substitution. In this regard, the tamoxifen-regulated system would promote the application of B-lineage targeted CAR T cell therapies even in curative settings where immunoglobulin replacement becomes limiting.

During repeated antigen exposure with alternating on/off states, inducible CAR T cells effectively eradicated CD20+ tumor cells, while the conventional constitutively expressed CAR did not elicit anti-tumor activity in the third round of antigen encounter (Figure 2g). The loss of robust effector function by the conventional constitutively expressed CAR T cells might result from a state of exhaustion due to sustained CAR signaling [51,52]. Defined, alternating on and off phases of CAR expression and, thus, calibration of the activation potential, could reduce chronic signaling and prevent exhaustion $[23,53,54]$. In this way, titratable CARs could have high therapeutic value far beyond their increased safety.

This proof of concept study demonstrated the use of tamoxifen-regulated zinc finger proteins for the controlled and fine-tuned onset of transgene expression in primary $\mathrm{T}$ cells. The activity of inducible anti-CD20 CAR T cells was strictly dependent on the presence of the inducer drug with no background CAR expression, anti-tumor activity, or cytokine secretion in the non-induced state both in vitro and in vivo. The absence of background expression of the 4-OHT-regulated transcriptional control system studied here distinguishes it from the Tet-on system with reported basal expression of anti-CD19 CAR $[26,27]$ in the absence of doxycycline. Moreover, the possibility of regulating the transcriptional output via the number of zinc finger binding sites, adds an additional modality for the adjustment of the transcriptional output beyond drug dosing. The system described here is under further investigation for translation towards clinical use and is intended to become a flexible platform applicable to any CAR T cell therapy beyond B cell malignancies, e.g., in solid tumors, where temporal and tunable control of CAR T cell function will be essential to increase safety. For clinical application, a detailed risk analysis focusing on the potential immunogenicity of the synthetic transcription factor will be performed. 


\section{Material and Methods}

\subsection{Cell Lines}

For in vitro experiments, the Burkitt lymphoma cell line Raji as well as the melanoma cell line 526-Mel were transduced with lentiviral vectors encoding a GFP-firefly luciferase cassette. $\mathrm{GFP}^{+}$526-Mel cells were additionally modified to stably express CD20. For in vivo studies, a mouse-adapted RajiffLuc cell line was used [37]. All tumor cell lines were cultured in RPMI 1640 (Biowest, Nuaillé, France) supplemented with $2 \mathrm{mM}$ glutamine (Lonza, Basel, Switzerland) and 10\% fetal bovine serum (FBS, Biochrome, Berlin, Germany). The human embryonic kidney cell line 293 T was cultured in Dulbecco's modified Eagle medium (Biowest, Nuaillé, France) supplemented with 10\% FBS.

\subsection{Generation of CAR Constructs and Lentiviral Vector Production}

The sequence of the synthetic transcription factor was ordered (ATUM, Newark, CA, USA) and cloned into a second-generation vector system (Miltenyi Biotec, Bergisch Gladbach, Germany) whereby the constitutive and inducible part were incorporated in an inverted orientation. The construction of the inducible anti-CD20 CAR plasmid was based on Beerli et al. [35]. The synthetic transcription factor composed of the N1 zinc finger, the murine estrogen receptor (G525R), and VP64 are constitutively expressed under the regulation of the human PGK promoter. $\triangle$ LNGFR serves as transduction marker as well as enrichment tag and is co-expressed with the synthetic transcription factor at equimolar levels from a single RNA transcript via a P2A sequence [55]. The synthetic transcription factor binds to up to five response elements upstream of the E1b minimal promoter and induces the transcription of a 2nd generation anti-CD20 CAR incorporating a leader sequence from huGM-CSFR, an anti-CD20 scFv based on Leu-16, CD8 hinge, and transmembrane domain, as well as the cytoplasmic domains of 4-1BB and CD3乙 [37]. For experiments with focus on induction dynamics, the anti-CD20 CAR cassette was exchanged to a sequence encoding destabilized GFP [56]. The conventional anti-CD20 CAR is constitutively expressed under the control of the human PGK promoter and is based on the same sequence as the inducible anti-CD20 CAR. Lentiviral particles were generated by the transient transfection of HEK $293 \mathrm{~T}$ cells using polyethylenimine. LV containing supernatants were concentrated by overnight centrifugation $(5380 \mathrm{~g}, 24 \mathrm{~h})$ and pelleted LVs were resuspended in PBS before storing at $-80^{\circ} \mathrm{C}$. LV titers were determined by the transduction of SupT1 and flow cytometric analysis of $\triangle$ LNGFR expression.

\subsection{Generation and Expansion of Inducible CAR T Cells}

Buffy coats and non-mobilized leukapheresis were obtained from healthy volunteer donors from the DRK Dortmund and Ulm. Human PBMCs were purified by density gradient centrifugation using Pancoll solution (Pan-Biotech, Aidenbach, Germany). Primary human $\mathrm{T}$ cells were isolated from PBMCs by negative bead selection according to manufacturer's recommendations (Pan T cell isolation kit, Miltenyi Biotec, Bergisch Gladbach, Germany) and activated using MACS GMP T Cell TransAct (Miltenyi Biotec, Bergisch Gladbach, Germany). T cells were cultured in TexMACS GMP medium (Miltenyi Biotec, Bergisch Gladbach, Germany) supplemented with $12.5 \mathrm{ng} / \mathrm{mL}$ of recombinant human IL-7 and $12.5 \mathrm{ng} / \mathrm{mL}$ of recombinant human IL-15 (Miltenyi Biotec, Bergisch Gladbach, Germany). T cells were transduced using lentiviral vectors $24 \mathrm{~h}$ after stimulation using an MOI of 5 to maintain the vector copy number of the drug product below 5 . T cells were washed 3 days after stimulation to remove MACS GMP T Cell TransAct and lentiviral particles. T cells were expanded for 13-14 days with the addition of fresh culture medium every 2-3 days, before the experiments were started. Timing of $\mathrm{T}$ cell generation, including activation, transduction, and addition of medium was kept consistent for experiments comparing multiple donors and CAR constructs. 


\subsection{Induction of Transgene Expression}

T cell numbers were adjusted to $5 \times 10^{4}$ transduced T cells $/ \mathrm{mL}$ and transgene transcription was induced by the addition of the indicated concentration of (Z)-4-hydroxytamoxifen (SigmaAldrich, St. Louis, MO, USA), (Z)-endoxifen (Axon Medchem, Groningen, The Netherlands) or a 1:9 mixture thereof (stock: $1 \mu \mathrm{M}(\mathrm{Z})$-4-hydroxytamoxifen, $9 \mu \mathrm{M}(\mathrm{Z})$-endoxifen) directly to the culture medium. Transgene expression was analyzed at the indicated time point by flow cytometry.

\subsection{Flow Cytometry Analysis}

Transduction efficiency was determined by flow cytometry staining of $\mathrm{T}$ cells using an APC-labelled anti-LNGFR antibody according to manufacturer's recommendations (10 $\mathrm{min}$ at $4-8{ }^{\circ} \mathrm{C}$, Miltenyi Biotec, Bergisch Gladbach, Germany). Anti-CD20 CAR expression was detected using anti-CD20 CAR detection reagent linked to PE $\left(10 \mathrm{~min}\right.$ at $4-8{ }^{\circ} \mathrm{C}$, Miltenyi Biotec, Bergisch Gladbach, Germany). To exclude dead cells, propidium iodide was added to the stained cells directly before sample acquisition at the MACSQuant Analyzer. MACSQuantify 2.13.0 or Flow Logic software 7.2.1 was used for data analysis.

\subsection{Cellular Cytotoxicity Assay}

T cells were co-cultured with $1 \times 10^{4}$ target cells $\left(\mathrm{GFP}^{+}\right.$Raji or $\left.\mathrm{GFP}^{+} \mathrm{CD} 20^{+} 526-\mathrm{Mel}\right)$ at indicated effector-to-target cell $(\mathrm{E}-\mathrm{T})$ ratios in the presence of stated concentrations of 4-OHT, endoxifen, or a combination thereof. Prior to each experiment, T cell numbers were adjusted to LNGFR expression implicating equal transduced and total T cell numbers in each well. To assess the cytolytic activity of inducible CAR T cells either the outgrowth of tumor cells was monitored over time using a live-cell imaging device (IncuCyte, Essen BioScience, Ann Arbor, MI, USA) or specific lysis was determined after the quantification of living target cells using the MACS Quant Analyzer $40 \mathrm{~h}$ after co-culture set-up. Specific lysis was calculated according to the following formula: \% specific lysis $=1-$ (cell count [sample]/cell count [target cell]). $\mathrm{EC}_{50}$ values were obtained by fitting log-transformed and normalized data using non-linear regression with GraphPad Prism 8. All samples were run in duplicates.

\subsection{Cytokine Secretion Assay}

Transduced as well as untransduced T cells were cultured with targets cells in a 1:1 ratio $\left(1 \times 10^{4}\right.$ cells per well each $)$ in the presence of the indicated concentration of 4-OHT, endoxifen or a combination thereof. After $40 \mathrm{~h}$, the cytokine secretion of $\mathrm{T}$ cells was determined in the supernatant of the co-culture using MACSPlex Cytokine $12 \mathrm{Kit}$, human (Miltenyi Biotec, Bergisch Gladbach, Germany), according to the manufacturer's protocol.

\subsection{Xenograft Mouse Model and Bioluminescent Imaging}

All animal experiments were approved by the ethical committee on animal care and use in Nordrhein-Westfalen, Germany (approval number: 81-02.04.2018.A326). For tumor establishment $3 \times 10^{5}$ or $4 \times 10^{5}$ mouse-adapted RajiffLuc cells were injected i.v. into the tail vein of NSG mice (NOD.Cg-Prkdcscid IL2rgtm $\left.{ }^{t m j l} / \mathrm{SzJ}\right)$. Tumor growth was monitored using an IVIS Lumina III instrument (Perkin Elmer, Waltham, MA, USA) 6 min after the i.p. injection of $100 \mu \mathrm{L}(30 \mathrm{mg} / \mathrm{mL}) \mathrm{D}$-Luciferin $\left(\mathrm{K}^{+}\right.$Salt) Bioluminescent Substrate (GoldBio, St Louis, MO, USA). Images were analyzed using Living Image, version 4.5.2., software (Perkin Elmer, Waltham, MA, USA) and the bioluminescent signal for each mouse was expressed in photon flux (photons per second). $3 \times 10^{6}$ transduced T cells (in total $1.1 \times 10^{7}$ $\mathrm{T}$ cells) were infused i.v. 5 days after tumor engraftment. Non-transduced T cells and an untreated group served as controls. Tamoxifen (Sigma-Aldrich, St. Louis, MO, USA) dispersed in $50 \mu \mathrm{L}$ peanut oil (Sigma-Aldrich, St. Louis, MO, USA) was administered i.p. every $24 \mathrm{~h}$ or $48 \mathrm{~h}$ to untreated (=tumor only), untransduced, and inducible CAR $\mathrm{w} /$ Tam groups. Direct CAR and inducible CAR w/o groups received oil injections without tamoxifen. Blood samples were collected from the Vena facialis on day 2 post $\mathrm{T}$ cell injection 
and processed to generate plasma for the measurement of plasma cytokines via MACSPlex Cytokine 12 Kit, human (Miltenyi Biotec, Bergisch Gladbach, Germany). For ex vivo analysis, mice were sacrificed and femur and tibia of both legs were flushed with RPMI to retrieve bone marrow isolates. Spleens were disrupted manually. Red blood cells were lysed and cells were stained for flow cytometry analysis or expanded ex vivo after restimulation.

\subsection{Statistical Analysis}

Statistical analysis was performed using GraphPad Prism 8 software (GraphPad, San Diego, CA, USA). All data are represented as mean \pm s.d. unless otherwise noted. Data were analyzed for statistical differences using tests indicated in the figure legends.

\section{Conclusions}

This study demonstrates the feasibility of CAR expression control in primary T cells using a zinc finger-based transcription factor that is responsive to metabolites of the clinically approved drug tamoxifen. The system is characterized by absence of background expression, and enabled time- and dose-dependent induction of anti-CD20 CAR expression, as well as fine-tuning of cytolytic activity against target cells, both in vitro and in vivo. This system may be readily applied for regulation of other CARs for which an improved control of expression is required.

Supplementary Materials: The following are available online at https:/ /www.mdpi.com/article/ 10.3390/ cancers13194741/s1, Figure S1: 4-OHT dependent induction of anti-CD20 CAR expression, Figure S2: Cytotoxic activity of inducible anti-CD20 CAR T cells against Raji and antigen negative 526-Mel cells in vitro, Figure S3: Modulation of inducible anti-CD20 CAR T cells in vivo by inducer dose and injection interval, Figure S4: Induction of anti-CD20 CAR expression in ex vivo cultivated $\mathrm{T}$ cells, Table S1: Comparison of transduction frequencies of inducible and conventional (direct) anti-CD20 CAR T cells

Author Contributions: Conceptualization, B.K., W.K., A.R., J.M. and A.D.K.; Formal analysis, B.K.; Investigation, B.K., F.E., A.R., W.A.R. and B.D.; Methodology, D.L., S.D. and D.S.; Supervision, J.M. and A.D.K.; Writing-original draft, B.K. and J.M.; Writing—review and editing, B.K., F.E., W.K., A.R., W.A.R., N.C., B.D., B.W., N.W., D.L., S.D., D.S., S.L., C.R., M.A., J.M. and A.D.K.; J.M. and A.D.K. share senior authorship. All authors have read and agreed to the published version of the manuscript.

Funding: This research received no external funding.

Institutional Review Board Statement: All animal experiments follow institutional guidelines and regulations and were approved by the by the ethical committee on animal care and use in North Rhine-Westphalia, Germany (Approval number: 81-02.04.2018.A326).

Informed Consent Statement: The study was approved by the institutional review board, and informed consent was obtained from all donors.

Data Availability Statement: The datasets presented in this study are available from the corresponding author on reasonable request.

Acknowledgments: We thank Timo Betz for critical discussion and careful reading of the manuscript.

Conflicts of Interest: Bettina Kotter, Fabian Engert, Wael Rawashdeh, Nicole Cordes, Britta Drees, Brian Webster, Niels Werchau, Dominik Lock, Sandra Dapa, Mario Assenmacher, Andrew Kaiser and Joerg Mittelstaet are employees of Miltenyi Biotec. Winfried Krueger, Andre Roy and Dina Schneider are employees of Lentigen, a Miltenyi Biotec company. No competing financial interests exist for the remaining authors. 


\section{References}

1. Neelapu, S.S.; Locke, F.L.; Bartlett, N.; Lekakis, L.J.; Miklos, D.B.; Jacobson, C.A.; Braunschweig, I.; Oluwole, O.O.; Siddiqi, T.; Lin, Y.; et al. Axicabtagene Ciloleucel CAR T-Cell Therapy in Refractory Large B-Cell Lymphoma. N. Engl. J. Med. 2017, 377, 2531-2544. [CrossRef]

2. Maude, S.L.; Laetsch, T.W.; Buechner, J.; Rives, S.; Boyer, M.; Bittencourt, H.; Bader, P.; Verneris, M.R.; Stefanski, H.E.; Myers, G.D.; et al Tisagenlecleucel in Children and Young Adults with B-Cell Lymphoblastic Leukemia. N. Engl. J. Med. 2018, 378, 439-448. [CrossRef]

3. Seimetz, D.; Heller, K.; Richter, J. Approval of First CAR-Ts: Have we Solved all Hurdles for ATMPs? Cell Med. 2019, 11, 215517901882278. [CrossRef] [PubMed]

4. Yu, W.-L.; Hua, Z.-C. Chimeric Antigen Receptor T-cell (CAR T) Therapy for Hematologic and Solid Malignancies: Efficacy and Safety-A Systematic Review with Meta-Analysis. Cancers 2019, 11, 47. [CrossRef]

5. Bonifant, C.; Jackson, H.J.; Brentjens, R.J.; Curran, K.J. Toxicity and management in CAR T-cell therapy. Mol. Ther. Oncolytics 2016, 3, 16011. [CrossRef] [PubMed]

6. Neelapu, S.S.; Tummala, S.; Kebriaei, P.; Wierda, W.; Gutierrez, C.; Locke, F.L.; Komanduri, K.V.; Lin, Y.; Jain, N.; Daver, N.; et al. Chimeric antigen receptor T-cell therapy-Assessment and management of toxicities. Nat. Rev. Clin. Oncol. 2017, 15, 47-62. [CrossRef] [PubMed]

7. Neelapu, S.S. Managing the toxicities of CAR T-cell therapy. Hematol. Oncol. 2019, 37, 48-52. [CrossRef] [PubMed]

8. Kochenderfer, J.N.; Wilson, W.H.; Janik, J.E.; Dudley, M.E.; Stetler-Stevenson, M.; Feldman, S.A.; Maric, I.; Raffeld, M.; Nathan, D.-A.N.; Lanier, B.J.; et al. Eradication of B-lineage cells and regression of lymphoma in a patient treated with autologous T cells genetically engineered to recognize CD19. Blood 2010, 116, 4099-4102. [CrossRef] [PubMed]

9. Kochenderfer, J.N.; Dudley, M.E.; Feldman, S.A.; Wilson, W.H.; Spaner, D.E.; Maric, I.; Stetler-Stevenson, M.; Phan, G.Q.; Hughes, M.S.; Sherry, R.M.; et al. B-cell depletion and remissions of malignancy along with cytokine-associated toxicity in a clinical trial of anti-CD19 chimeric-antigen-receptor-transduced T cells. Blood 2012, 119, 2709-2720. [CrossRef]

10. Porter, D.L.; Hwang, W.-T.; Frey, N.V.; Lacey, S.F.; Shaw, P.A.; Loren, A.W.; Bagg, A.; Marcucci, K.T.; Shen, A.; Gonzalez, V.; et al. Chimeric antigen receptor $\mathrm{T}$ cells persist and induce sustained remissions in relapsed refractory chronic lymphocytic leukemia. Sci. Transl. Med. 2015, 7, 303ra139. [CrossRef] [PubMed]

11. Doan, A.; Pulsipher, M.A. Hypogammaglobulinemia due to CAR T-cell therapy. Pediatr. Blood Cancer 2017, 65, e26914. [CrossRef]

12. Weeks, J.C.; Tierney, M.R.; Weinstein, M.C. Cost Effectiveness of Prophylactic Intravenous Immune Globulin in Chronic Lymphocytic Leukemia. N. Engl. J. Med. 1991, 325, 81-86. [CrossRef] [PubMed]

13. Morgan, R.A.; Yang, J.C.; Kitano, M.; Dudley, M.E.; Laurencot, C.M.; Rosenberg, S.A. Case Report of a Serious Adverse Event Following the Administration of T Cells Transduced with a Chimeric Antigen Receptor Recognizing ERBB2. Mol. Ther. 2010, 18, 843-851. [CrossRef]

14. Lamers, C.H.; Sleijfer, S.; van Steenbergen, S.; van Elzakker, P.; van Krimpen, B.; Groot, C.; Vulto, A.; Bakker, M.D.; Oosterwijk, E.; Debets, R.; et al. Treatment of Metastatic Renal Cell Carcinoma with CAIX CAR-engineered T cells: Clinical Evaluation and Management of On-target Toxicity. Mol. Ther. 2013, 21, 904-912. [CrossRef] [PubMed]

15. Bonini, C. HSV-TK Gene Transfer into Donor Lymphocytes for Control of Allogeneic Graft-Versus-Leukemia. Science 1997, 276, 1719-1724. [CrossRef] [PubMed]

16. Thomis, D.C. A Fas-based suicide switch in human T cells for the treatment of graft-versus-host disease. Blood 2001, 97, 1249-1257. [CrossRef]

17. Straathof, K.C.; Pule, M.; Yotnda, P.; Dotti, G.; Vanin, E.F.; Brenner, M.K.; Heslop, H.E.; Spencer, D.M.; Rooney, C.M. An inducible caspase 9 safety switch for T-cell therapy. Blood 2005, 105, 4247-4254. [CrossRef]

18. Vogler, I.; Newrzela, S.; Hartmann, S.; Schneider, N.; von Laer, D.; Koehl, U.; Grez, M. An Improved Bicistronic CD20/tCD34 Vector for Efficient Purification and In Vivo Depletion of Gene-Modified T Cells for Adoptive Immunotherapy. Mol. Ther. 2010, 18, 1330-1338. [CrossRef] [PubMed]

19. Paszkiewicz, P.J.; Fräßle, S.P.; Srivastava, S.; Sommermeyer, D.; Hudecek, M.; Drexler, I.; Sadelain, M.; Liu, L.; Jensen, M.C.; Riddell, S.R.; et al. Targeted antibody-mediated depletion of murine CD19 CAR T cells permanently reverses B cell aplasia. J. Clin. Investig. 2016, 126, 4262-4272. [CrossRef] [PubMed]

20. Wu, C.-Y.; Roybal, K.T.; Puchner, E.M.; Onuffer, J.; Lim, W.A. Remote control of therapeutic T cells through a small molecule-gated chimeric receptor. Science 2015, 350, aab4077. [CrossRef]

21. Tamada, K.; Geng, D.; Sakoda, Y.; Bansal, N.; Srivastava, R.; Li, Z.; Davila, E. Redirecting Gene-Modified T Cells toward Various Cancer Types Using Tagged Antibodies. Clin. Cancer Res. 2012, 18, 6436-6445. [CrossRef] [PubMed]

22. Rodgers, D.T.; Mazagova, M.; Hampton, E.N.; Cao, Y.; Ramadoss, N.S.; Hardy, I.R.; Schulman, A.; Du, J.; Wang, F.; Singer, O.; et al. Switch-mediated activation and retargeting of CAR-T cells for B-cell malignancies. Proc. Natl. Acad. Sci. USA 2016, 113, E459-E468. [CrossRef]

23. Mestermann, K.; Giavridis, T.; Weber, J.; Rydzek, J.; Frenz, S.; Nerreter, T.; Mades, A.; Sadelain, M.; Einsele, H.; Hudecek, M. The tyrosine kinase inhibitor dasatinib acts as a pharmacologic on/off switch for CAR T cells. Sci. Transl. Med. 2019, 11, eaau5907. [CrossRef] [PubMed] 
24. Ma, J.S.Y.; Kim, J.Y.; Kazane, S.A.; Choi, S.-H.; Yun, H.; Kim, M.S.; Rodgers, D.T.; Pugh, H.M.; Singer, O.; Sun, S.B.; et al. Versatile strategy for controlling the specificity and activity of engineered T cells. Proc. Natl. Acad. Sci. USA 2016, 113, E450-E458. [CrossRef]

25. Brenner, M.J.; Cho, J.H.; Wong, N.M.; Wong, W.W. Synthetic Biology: Immunotherapy by Design. Annu. Rev. Biomed. Eng. 2018, 20, 95-118. [CrossRef]

26. Sakemura, R.; Terakura, S.; Watanabe, K.; Julamanee, J.; Takagi, E.; Miyao, K.; Kiyoi, H. A Tet-On Inducible System for Controlling CD19-Chimeric Antigen Receptor Expression upon Drug Administration. Cancer Immunol. Res. 2016, 4, 658-668. [CrossRef] [PubMed]

27. Gu, X.; He, D.; Li, C.; Wang, H.; Yang, G. Development of Inducible CD19-CAR T Cells with a Tet-On System for Controlled Activity and Enhanced Clinical Safety. Int. J. Mol. Sci. 2018, 19, 3455. [CrossRef]

28. Dreier, B.; Fuller, R.P.; Segal, D.; Lund, C.V.; Blancafort, P.; Huber, A.; Koksch, B.; Barbas, C.F. Development of Zinc Finger Domains for Recognition of the $5^{\prime}-\mathrm{CNN}-3^{\prime}$ Family DNA Sequences and Their Use in the Construction of Artificial Transcription Factors. J. Biol. Chem. 2005, 280, 35588-35597. [CrossRef]

29. Segal, D.; Dreier, B.; Beerli, R.R.; Barbas, C.F. Toward controlling gene expression at will: Selection and design of zinc finger domains recognizing each of the 5'-GNN-3' DNA target sequences. Proc. Natl. Acad. Sci. USA 1999, 96, 2758-2763. [CrossRef]

30. Bae, K.-H.; Kwon, Y.D.; Shin, H.-C.; Hwang, M.-S.; Ryu, E.-H.; Park, K.-S.; Yang, H.-Y.; Lee, D.-K.; Lee, Y.; Park, J.; et al. Human zinc fingers as building blocks in the construction of artificial transcription factors. Nat. Biotechnol. 2003, 21, 275-280. [CrossRef]

31. Dreier, B.; Beerli, R.R.; Segal, D.; Flippin, J.D.; Barbas, C.F. Development of Zinc Finger Domains for Recognition of the 5'-ANN-3' Family of DNA Sequences and Their Use in the Construction of Artificial Transcription Factors. J. Biol. Chem. 2001, 276, 29466-29478. [CrossRef]

32. Beerli, R.R.; Segal, D.; Dreier, B.; Barbas, C.F. Toward controlling gene expression at will: Specific regulation of the erbB-2/HER-2 promoter by using polydactyl zinc finger proteins constructed from modular building blocks. Proc. Natl. Acad. Sci. USA 1998, 95, 14628-14633. [CrossRef] [PubMed]

33. Beerli, R.R.; Dreier, B.; Barbas, C.F. Positive and negative regulation of endogenous genes by designed transcription factors. Proc. Natl. Acad. Sci. USA 2000, 97, 1495-1500. [CrossRef]

34. Gersbach, C.A.; Gaj, T.; Barbas, I.C.F. Synthetic Zinc Finger Proteins: The Advent of Targeted Gene Regulation and Genome Modification Technologies. Acc. Chem. Res. 2014, 47, 2309-2318. [CrossRef] [PubMed]

35. Beerli, R.R.; Schopfer, U.; Dreier, B.; Barbas, C.F. Chemically Regulated Zinc Finger Transcription Factors. J. Biol. Chem. 2000, 275, 32617-32627. [CrossRef]

36. Lock, D.; Mockel-Tenbrinck, N.; Drechsel, K.; Barth, C.; Mauer, D.; Schaser, T.; Kolbe, C.; Al Rawashdeh, W.; Brauner, J.; Hardt, O.; et al . Automated Manufacturing of Potent CD20-Directed Chimeric Antigen Receptor T Cells for Clinical Use. Hum. Gene Ther. 2017, 28, 914-925. [CrossRef] [PubMed]

37. Schneider, D.; Xiong, Y.; Wu, D.; Nölle, V.; Schmitz, S.; Haso, W.; Kaiser, A.; Dropulic, B.; Orentas, R.J. A tandem CD19/CD20 CAR lentiviral vector drives on-target and off-target antigen modulation in leukemia cell lines. J. Immunother. Cancer $2017,5,42$. [CrossRef]

38. Lien, E.A.; Søiland, H.; Lundgren, S.; Aas, T.; Steen, V.M.; Mellgren, G.; Gjerde, J. Serum concentrations of tamoxifen and its metabolites increase with age during steady-state treatment. Breast Cancer Res. Treat. 2013, 141, 243-248. [CrossRef]

39. Drent, E.; Poels, R.; Mulders, M.J.; Van De Donk, N.W.C.J.; Themeli, M.; Lokhorst, H.M.; Mutis, T. Feasibility of controlling CD38-CAR T cell activity with a Tet-on inducible CAR design. PLoS ONE 2018, 13, e0197349. [CrossRef] [PubMed]

40. Kadonaga, J.T. Perspectives on the RNA Polymerase II Core Promoter James. Wiley Interdiscip. Rev. Dev. Biol. 2012, 1, 40-51. [CrossRef] [PubMed]

41. Walker, A.J.; Majzner, R.G.; Zhang, L.; Wanhainen, K.; Long, A.H.; Nguyen, S.M.; Lopomo, P.; Vigny, M.; Fry, T.J.; Orentas, R.J.; et al. Tumor Antigen and Receptor Densities Regulate Efficacy of a Chimeric Antigen Receptor Targeting Anaplastic Lymphoma Kinase. Mol. Ther. 2017, 25, 2189-2201. [CrossRef] [PubMed]

42. Turatti, F.; Figini, M.; Balladore, E.; Alberti, P.; Casalini, P.; Marks, J.D.; Canevari, S.; Mezzanzanica, D. Redirected Activity of Human Antitumor Chimeric Immune Receptors is Governed by Antigen and Receptor Expression Levels and Affinity of Interaction. J. Immunother. 2007, 30, 684-693. [CrossRef] [PubMed]

43. Weijtens, M.E.M.; Hart, E.H.; Bolhuis, R.L.H. Functional balance between T cell chimeric receptor density and tumor associated antigen density: CTL mediated cytolysis and lymphokine production. Gene Ther. 2000, 7, 35-42. [CrossRef] [PubMed]

44. Eyquem, J.; Mansilla-Soto, J.; Giavridis, T.; Van Der Stegen, S.J.C.; Hamieh, M.; Cunanan, K.M.; Odak, A.; Gönen, K.M.C.M.; Sadelain, J.E.J.M. Targeting a CAR to the TRAC locus with CRISPR/Cas9 enhances tumour rejection. Nature 2017, 543, 113-117. [CrossRef] [PubMed]

45. Kisanga, E.R.; Gjerde, J.; Gonzaga, A.G.; Pigatto, F.; Pesci-Feltri, A.; Robertson, C.; Serrano, D.; Pelosi, G.; DeCensi, A.; Lien, E.A. Tamoxifen and Metabolite Concentrations in Serum and Breast Cancer Tissue during Three Dose Regimens in a Randomized Preoperative Trial. Clin. Cancer Res. 2004, 10, 2336-2343. [CrossRef] [PubMed]

46. Lorizio, W.; Wu, A.H.B.; Beattie, M.S.; Rugo, H.; Tchu, S.; Kerlikowske, K.; Ziv, E. Clinical and biomarker predictors of side effects from tamoxifen. Breast Cancer Res. Treat. 2011, 132, 1107-1118. [CrossRef]

47. Cuzick, J.; Forbes, J.F.; Sestak, I.; Cawthorn, S.; Hamed, H.; Holli, K.; Howell, A. Long-Term Results of Tamoxifen Prophylaxis for Breast Cancer-96-Month Follow-up of the Randomized IBIS-I Trial. J. Natl. Cancer Inst. 2007, 99, 272-282. [CrossRef] [PubMed] 
48. Gallicchio, L.; Lord, G.; Tkaczuk, K.; Danton, M.; Lewis, L.M.; Lim, C.K.; Flaws, J.A. Association of Tamoxifen (TAM) and TAM Metabolite Concentrations with Self-Reported Side Effects of TAM in Women with Breast Cancer. Breast Cancer Res. Treat. 2004, 85, 89-97. [CrossRef]

49. Guelen, P.J.; Stevenson, D.; Briggs, R.J.; De Vos, D. The bioavailability of Tamoplex (tamoxifen). Part 2. A single dose cross-over study in healthy male volunteers. Methods Find. Exp. Clin. Pharmacol. 1987, 9, 685-690.

50. Le, R.Q.; Li, L.; Yuan, W.; Shord, S.S.; Nie, L.; Habtemariam, B.A.; Przepiorka, D.; Farrell, A.T.; Pazdur, R. FDA Approval Summary: Tocilizumab for Treatment of Chimeric Antigen Receptor T Cell-Induced Severe or Life-Threatening Cytokine Release Syndrome. Oncology 2018, 23, 943-947.

51. Wherry, E.J.; Kurachi, M. Molecular and cellular insights into T cell exhaustion. Nat. Rev. Immunol. 2015, 15, 486-499. [CrossRef] [PubMed]

52. Philip, M.; Fairchild, L.; Sun, L.; Horste, E.L.; Camara, S.; Shakiba, M.; Scott, A.; Viale, L.S.A.; Lauer, P.; Merghoub, T.; et al. Chromatin states define tumour-specific T cell dysfunction and reprogramming. Nature 2017, 545, 452-456. [CrossRef] [PubMed]

53. Feucht, J.; Sun, J.; Eyquem, J.; Ho, Y.-J.; Zhao, Z.; Leibold, J.; Dobrin, A.; Cabriolu, A.; Hamieh, M.; Sadelain, M. Calibration of CAR activation potential directs alternative T cell fates and therapeutic potency. Nat. Med. 2018, 25, 82-88. [CrossRef] [PubMed]

54. Youngblood, B.; Davis, C.W.; Ahmed, R. Making memories that last a lifetime: Heritable functions of self-renewing memory CD8 T cells. Int. Immunol. 2010, 22, 797-803. [CrossRef]

55. Kim, J.H.; Lee, S.-R.; Li, L.-H.; Park, H.-J.; Park, J.-H.; Lee, K.Y.; Kim, M.-K.; Shin, B.A.; Choi, S.-Y. High Cleavage Efficiency of a 2A Peptide Derived from Porcine Teschovirus-1 in Human Cell Lines, Zebrafish and Mice. PLoS ONE 2011, 6, e18556. [CrossRef]

56. Li, X.; Zhao, X.; Fang, Y.; Jiang, X.; Duong, T.; Fan, C.; Huang, C.-C.; Kain, S.R. Generation of Destabilized Green Fluorescent Protein as a Transcription Reporter. J. Biol. Chem. 1998, 273, 34970-34975. [CrossRef] 